\title{
THEORETICAL AND PRACTICAL SECURITY ASPECTS OF CRIME SCENE INVESTIGATIONS AND EVALUATION OF EVIDENCE
}

\author{
Slobodan Oklevski, PhD \\ Faculty of Security - Skopje, \\ Ministry of Interior - Forensic Department, \\ E-mail: 0_slobodan@yahoo.com
}

\section{Abstract:}

Detecting and locating physical evidence during crime scene investigation requires special expertise and experience which should contribute to proper assessment, access, organization and coordination of the investigative activities. Securing the scene of the investigation is very important and, perhaps, it is one of the key activities on which all further processes depend. As a logical and intellectual act, the inspection, above all, represents a mental reconstruction of the dynamics of the criminal act that happened, with two objectives: the first objective refers to being able to understand the chronology of the activities i.e. the analysis of the logical layout of the physical evidence; and the second one, consequently to the first, refers to predicting the places where the latent physical changes could have happened. Trace evidence which is detected during the crime scene should represent logical consequence of a criminal act i.e. they should be in causal relation with the actions undertaken by the perpetrator or perpetrators. For these reasons recovering evidence does not mean simply collecting and packing it up, but implementation of appropriate strategy as a starting point for investigating the crime scene, which presents an organized, methodical, systematic and logical process.

Key words: crime scene investigation, evidence, fingermarks, evaluation.

\section{Introduction:}

Detecting and locating physical evidence during crime scene investigation requires special expertise and experience which should contribute to proper assessment, access, organization and coordination of the investigative activities. Securing the scene of the crime is very important and perhaps, it is one of the key activities on which all further processes depend. As a logical and intellectual act, the inspection, above all, represents a mental reconstruction of the dynamics of the criminal act that happened, with two objectives: the first objective refers to being able to 


\section{Security}

understand the chronology of the activities i.e. the analysis of the logical layout of the visible physical evidence i.e. macro traces; and the second one, consequently to the first, refers to predicting the places where the latent physical changes or micro traces could have happened. This means that the crime scene, as a matrix of all activities, is the core where all the evidence is recovered. The logic i.e. or the way of their occurrence is, perhaps, crucial for the system of proving the crime. In this context we can state the legal definition of Inspection from the Official gazette No. 150 from 18 November 2010, Article 233 which states that: "(1) Any crime scene investigation shall be conducted by the public prosecutor and with his or her authorization, also by the judicial police, if an immediate observation is required in order to establish or clarify some important fact in the procedure". For example, the Slovenian Criminal procedure code ZKP-NPB29 has a very similar approach where in Article 245 it is stated that "An inspection is carried out when determination or explanation of an important fact for the proceedings calls for immediate observation".

It may be noted that laws provide general and even superficial approach in defining this investigative activity. By means of intensive interpretation, we may conclude that the clarification, determination or explanation of an important fact is made by inspection, analysis and appropriate forensic expertise of physical evidence, i.e. directly or indirectly, other facts are proven to be in correlation with the core of the criminal act. Vodinelic (1985) defines crime scene investigation as an investigative court activity whose content is examined through direct sensory perception, verification and clarification of certain facts and circumstances relevant to the criminal proceedings. The sensory observation for example listening, watching or smelling are no longer one of the most important factors during the crime scene investigation. It becomes an often practice, during the inspection, to recover latent and micro evidence that has strong evidential significance, and at the same time have no great connection with the senses of the investigators at the crime scene. Henry Lee (2001) argues that the inspection is more than processing or documenting at the crime scene, or just collecting and packing up physical traces. In the basis of any crime scene investigation is the ability of the investigator to recognize the important and potential physical evidence. Finally, an appropriate investigation is a starting point in establishing what has happened, in other words, it is an initiative for reconstruction of the crime scene, which presents an organized, methodical, systematic and logical process.

Trace evidence which is detected during the crime scene investigation should represent logical consequence of a criminal act i.e. they should be in causal relation with the actions undertaken by the perpetrator or perpetrators. For these reasons providing evidence does not mean simply collecting and packing it up, but it also means doing a situational analysis during which you have to ask and perhaps answer the following questions:

- What is the condition of the evidence which are collected?

- The way the evidence occurred and if the place where it was found is logical;

- Whether the position of the evidence where it was found is original or the evidence was moved (intentionally / unintentionally);

- Whether the collected item is a carrier of other micro or latent traces; 
- Whether the evidence 'speaks' or can help about the mental reconstruction of the crime scene;

- What kind of forensic expertise it can be exposed to i.e. why it is collected;

- Whether it is worth collecting some evidence or the forensic scientist is just trying to show some activity.

Taking into account the complex mental process which is part of the process of collecting evidence we will try to define it as follows: "physical evidence is any material change caused intentionally or unintentionally, visible or invisible to the naked eye, which is in the causal link with the criminal act or any other event whose clarification is connected to the forensics." (Radojica, 2000).

As a logical consequence to the overall forensic analysis is the process of proving, during which certain actions are taken in order for the court to form an opinion based on the existence of legally relevant facts, which are highly relevant in reaching the right verdict in the criminal proceeding. Theoretically, the value of separate physical evidence that determines or reveals legally relevant facts upon which, directly or indirectly, a certain person is considered to have committed a crime is, undoubtedly, of particular importance. In this context, understanding the core of the criminal act that has happened is a necessary prerequisite in order to apply appropriate methodology of analysis and expertise of trace evidence.

What transforms the trace into evidence is the possibility, with a forensic, criminal and logical interpretation, to prove someone's presence at the crime scene in an interval when the criminal act has occurred. This will define the evidence as criminal relevant information which is contained in the people and objects obtained in legal process with the use of planned process (Vodinelic, 1985). Its evaluation should not be an arbitrary act, but a procedure with a use of objective criteria, such as the laws of logic, the rules of general human experience, common sense and substantial knowledge in field of criminalistics. The evidence contains evidential basis which is already known, established fact which is used to confirm the validity of any other fact, which is to be determined in this particular case and is a subject to prove (Matovski, 2003). In foreign references, there is a different approach to the definition of physical evidence, which may be defined as any trace of different size through which with a scientific analysis and investigation can be proved that a certain criminal act has happened (Eckert, 1995). Furthermore, according to these authors, evidence in criminal investigations may be used as follows:

1. To define the elements of the criminal act- evidence that prove the criminal is committed;

2. To lead the investigation - for example the type of vehicle in an accident with fatal consequences when the driver left the scene;

3. To connect the crime scene or the victim with the suspect - this connection may be established by analyzing different types of traces such as papillary lines, blood, hair, etc.;

4. To confirm or deny the alibi of the suspect;

5. To identify the suspect - identification using fingerprints, palm prints or foot prints and DNA profile; 
6. To be able to confirm the confession of the suspect;

7. To be able to acquit the suspect, and

8. To provide expert testimony in front of the judicial authorities. (Eckert, 1992)

According to Jack V. Matson (2004) physical evidence is relevant information presented to the court in order to support or reject the case in criminal proceedings. Formal logic shows that in order to determine legally relevant facts, when using direct or indirect evidence, a process of logical conclusion is used, and the process itself goes through certain phases before the conclusion is made. In other words, the process of logical conclusion is not distinctive only for the process of indirect conclusion, but for the direct one as well (Krapac, 1982). What characterizes the evidence is its cognitive or evidential value which means the ability to establish the facts which, directly or indirectly, point to the perpetrator.

In the modern theory of Criminal Procedure Law, the principle of free evaluation of evidence is widely accepted. In the Macedonian Criminal Procedure Code (Official Gazette no. 150, 18 November 2010), Article 16 stipulates the principle of free evaluation of evidence as follows: "(1) The right of the court and any state authorities which participate in the criminal procedure to evaluate the existence or non-existence of facts shall not be bound nor limited by any special formal rules of evidence." Therefore, there is a free judicial conviction when the judge evaluates the presented evidence for existence of facts, subjecting them to its own logical and psychological analysis while not being bound by any statutory rules for the evaluation of the evidence. The Slovenian Law on Criminal Procedure ZKP-NPB29 is very similar, where in Article 18 is stated that: "(1) The right of the court and of state bodies participating in criminal proceedings to evaluate the facts presented shall not be bound or limited by any specific formal rules of evidence". Contrary to the free judicial conviction in the American criminal justice system, as early as 1923 , it is required satisfying Frye standard, where the court must decide whether the questioned procedure, technique, or principle is "generally accepted" by a meaningful segment of the relevant scientific community. In practice, this approach required the proponent of a scientific test to present to the court a collection of experts who could testify that the scientific issue before the court is generally accepted by the relevant members of the scientific community (Saferstein, 2006). Specifically, Rule 702 of the Federal Rules of Evidence deals with the admissibility of expert testimony: If scientific, technical, or other specialized knowledge will assist the trier of fact to understand the evidence or to determine a fact in issue, a witness qualified as an expert by knowledge, skill, experience, training, or education, may testify thereto in the form of an opinion or otherwise, if (1) the testimony is based upon sufficient facts or data, (2) the testimony is the product of reliable principles and methods, and (3) the witness has applied the principles and methods reliably to the facts of the case.

In continuation of the paper we will provide theoretical reference to proving and processing of fingerprints as one of the oldest known and recognized scientific evidence. The evaluation of the evidential and cognitive value of fingermarks in the form of direct evidence, on the one hand, includes the value of the content of the evidence, and on the other hand includes the evaluation 
of the legitimacy of the item on which the papillary traces are developed. The logical value of the direct evidence gives us a categorical conclusion, which directly proves certain facts, such as if a certain person is really the committer of the crime or if the evidence occurred during and because of the criminal act. This means that in the process of establishing the facts, the validity of the final conclusion is not put into question, unless we challenge the legitimacy of the evidence holder. In this case, the surface or the object on which the traces are visualized plays an important role in several aspects:

- Fingermarks are visualized on the surface of an object which was used in the criminal act (gun, knife)

- Fingermarks are visualized on the surface of an object which is obtained with a criminal act (money or other items)

- Fingermarks are visualized on the surface of an object which is used for overcoming obstacles (tools, drills, pliers)

- Fingermarks are visualized on the surface of an object because of which the criminal act is committed (drug packaging)

- Fingermarks are visualized on the surface of objects which are removed as obstacles in order to reach the desired primary purpose, i.e. they are primarily deposited by the owner and then moved by the perpetrator.

- Fingermarks are visualized on a surface which is not a public place or in a private apartment where the perpetrator could not be present in normal conditions.

The contaminant containing developed latent prints is a key component in the process of identifying the suspect as well. The contents determination of the dactyloscopic evidence defines the material and formal aspects of its occurrence, which means that the basic role of the judge is not only to determine whether these fingermarks occurred during the criminal act, but to determine the dynamics of their occurrence i.e. touching, grasping, pushing, catching the object or surface on which the traces are visualized.

The expert may only confirm if the object was touched in a certain case, i.e. if the disputed and undisputed samples are identical when the creation of the dactyloscopic evidence actually begins. Vodinelic (1985) argues that dactyloscopic evidence, regarding the guilt of committing a certain crime, is consisted of four levels of proving, such as:

- The first evidence shows that the provided fingermarks are not planted at the crime scene. This negative evidence has eliminative value and besides proving the identity of a certain person and his presence at the crime scene, it should undoubtedly guarantee the actual situation of the crime scene as well. This equally applies to movable objects res mobiles and fixed objects.

- Another piece of evidence shows that the fixed fingermarks at the crime scene really comes from the suspect. This view comprises two aspects namely: whether the suspect was known before the traces were identified, so with the dactyloscopic expertise the indications made upon other facts are confirmed, or the suspect was revealed only after traces were identified. This is the basis upon which a story can be recreated and it shows whether 


\section{Securitity}

that presence is marked during committing the criminal act, and as such, if it becomes an indication for being a participant in the act.

- The third piece of evidence is that the obtained trace at the crime scene occurred during commiting the criminal act. This becomes an indication for being a part of that criminal act and even more likely that this person is actually the perpetrator of the crime.

- The fourth piece of evidence is that not only the fixed trace occurred during committing the criminal act at the crime scene, but it has also occurred because of committing the crime.

There is always one question to be asked. What does it mean to be present at the crime scene? Does that mean that the person from whom the traces originate undoubtedly committed the crime?

The fingermarks on their own do not prove that a certain person has committed a certain crime. They only prove that the suspect on one occasion was at the crime scene, which it does not solve the question if he is the perpetrator of the crime. Before we even start the process of identification and individualization of the traces of papillary lines, it's crucial that they are processed at the crime scene first. This is an essential process that both from criminal and normative aspect should provide legitimacy of material evidence. On the one hand, the legitimacy should ensure the legality of the procedure in which they are provided and processed, and on the other hand the legitimacy should ensure the inviolability of the traces in terms of those facts which are used to prove them. Dactyloscopic analysis of fingermarks, scientifically, should ensure objectivity, validity, systematicity and methodology of procedures and expertise. To sum up, processing of fingermarks several aspects, as follows:

1. Mental reconstruction of the dynamics of the illegal action at the crime scene, where the criminalists get familiar thoroughly with the material changes which can be seen visually at the crime scene;

2. Detection and visualization of fingermarks or using appropriate forensic techniques during the crime scene investigations;

3. Marking, sketching and photographing of the traces respectively, as well as their location and relation to other traces at the crime scene; and

4. Obtaining in terms of collecting, packing up and delivering of the traces in the forensic laboratory for further analysis.

Mental reconstruction is a necessity for proper criminal (forensic) processing at the crime scene, and proper detection of fingermarks which is directly related to the dynamics of the illegal action undertaken by the perpetrator, the type of criminal act which was committed and the contact of the perpetrator with the crime scene. Basically this is an initial approach which is primarily directed towards achieving the main objectives of the contact theory written by prof. Edmond Locard. 


\begin{tabular}{|l|r|}
\hline taking bribe & $0,37 \%$ \\
\hline rape & $1,11 \%$ \\
\hline murder & $1,11 \%$ \\
\hline drug trafficking & $2,22 \%$ \\
\hline terrorism & $1,48 \%$ \\
\hline robbery & $2,22 \%$ \\
\hline motor vehicle theft & $3,70 \%$ \\
\hline Illicit arms trafficking & $5,18 \%$ \\
\hline robbery & $82,50 \%$ \\
\hline
\end{tabular}

Table 1: Percentage of fingermarks in individual criminal acts on the territory of the Republic of Macedonia for the period 2001-2005, which are solved on the basis of dactyloscopic evidence.

From the attached statistical analysis of table 1, for the period 2001-2005, we can see the percentages of fingermarks in individual criminal acts which are solved based on dactyloscopic evidence. Certainly, there is a reason for this percentage ratio and it depends on several factors (Oklevski 2009):

- The space where the criminal act is committed. It may be open or closed, clean or previously contaminated with waste or other materials,

- The types of surfaces and materials present at the crime scene,

- Is there is a need to go in or how to go in the space, whether to be broken into or simply there are no obstacles,

- The use of appropriate tools or means with which the criminal act is done or the space is broken into,

- The contact of the perpetrator with the interior of the crime scene,

- The contact the perpetrator with the crime victim, i.e. if the victim is robbed, beaten, raped, etc.

- If the dactyloscopic evidence proves the presence of the perpetrator at the crime scene, the contact with the weapon with which the crime was committed or the contact with the victim.

\section{Conclusions}

Although the second part of the paper is focused on the fingerprints, our goal was to discuss universal theories that evidence should complement or increase criminalistic logic in the process 
of proving the crime. In this context we say in conclusion that there are two aspects of analysis of physical evidence: material and formal. The both aspects should ensure the inviolability of the evidentiary importance of the evidence. The formal aspect refers to detection and interpretation of material changes which reflect the dynamics of the action committed as a result of the activity of the perpetrator. Such an approach towards the material changes that happened at the crime scene refers primarily to their recognition i.e. detection and to the information they can provide. From this moment on, the creation of material evidence begins, and it must be highlighted that its interpretation is always versus the causal course (s) of the criminal act. The material aspect in the interpretation of evidence covers the presence of qualitative and quantitative characteristics that are sufficient to perform identification and individualization of the sample in order to create important facts for criminal proceedings.

\section{References}

1. Eckert, W. G. (1995). Introduction to Forensic Sciences 2d ed. Boca Raton: CRC Press, Boca Raton, FL.

2. Krapac, D. (1982). Neposrednil posrednidokazi ukrivičnom postupku. Zagreb: Informator.

3. Matson, J. V. (2004). Effective Expert Witnessing, 4th edition, Boca Raton: CRC Press.

4. Lee, H. (2001). Crime Scene Handbook. New York: Academic Press.

5. Matovski, N. (2003). Krivično procesno pravo - opšt del. Skopje: Praven fakultet - Skopje.

6. Oklevski, S. (2009). "Latent Fingerprints Analysis in violent crimes investigation". Revia Criminalistica, 22.

7. Radojica, M. (2000). Kriminalistika tehnika. Beograd.

8. Saferstein, R. (2006). Criminalistics. An Introduction to Forensic Science, 9th edition. New Jersey: Pearson.

9. Vodinelic, V. (1985). Kriminalistika otkrivanje i dokazivanje. Skopje. 